\title{
Mastalgia as an atypical presentation of hepatocellular carcinoma: a case report
}

\author{
AbdulAziz Mohammad Al-Sharydah ${ }^{*}$, Abdulrhman Hamad Al-Abdulwahhab", Ibrahim Abobaker Alghnimi', \\ Mohammed A. El Shawarby ${ }^{2}$ and Faisal Ahmad Katbi ${ }^{3}$
}

\begin{abstract}
Background: As the incidence of hepatocellular carcinoma (HCC) diagnoses in Saudi Arabia has recently increased due to better diagnostic techniques, the incidence of diagnosed HCC metastasis has also increased. Here, we report a case of HCC metastasis to the rib with an initially atypical presentation of mastalgia caused by extrahepatic metastasis.

Case presentation: A 31-year-old woman with a prior hepatitis B viral infection presented with a mass in the left breast accompanied by mastalgia for a 6-month duration. The patient's liver enzymes were elevated, and her serum a-fetoprotein level was particularly high. Computed tomography of her chest and abdomen showed a soft-tissue mass adhering to the upper chest wall, rib deterioration, and multiple hepatic lesions. A needle biopsy was immunohistochemically analyzed for Glypican-3, Pan-CK, and CK7 and was confirmed to be metastatic HCC.

Conclusions: This metastatic HCC case is unique because it initially presented as mastalgia. We should consider the possibility of metastatic disease when assessing patients with unusual presentations who have risk factors for metastatic carcinoma.
\end{abstract}

Keywords: Metastatic hepatocellular carcinoma, Extrahepatic, Bone metastasis, Liver cancer

\section{Background}

Hepatocellular carcinoma (HCC) is the 3rd most common carcinoma worldwide. In Saudi Arabia, it accounts for approximately $4.8 \%$ of all tumors. HCC is the 4 th most common cancer in men and the 8th most common cancer in women [1] and is defined as an epithelial tumor that arises from the malignant transformation of hepatocytes. HCC is the most common primary liver malignancy and is often discovered in patients who present with cirrhosis or other chronic liver diseases [2]. Extrahepatic metastasis (Em) of HCC (EmHCC) is usually seen in a terminal stage and has an aggressive progression [3]. EmHCC manifests in approximately half of HCC cases and is most commonly found in the lung, lymph nodes, or bones [4]. Bone metastasis accounts for $1.6-16 \%$ of HCC metastasis. Em occurs most commonly to the ribs (six reported cases), followed by the mandible, the humerus, the femur, the iliac bone, and the

\footnotetext{
* Correspondence: amsharydah@uod.edu.sa

'Department of Radiology, King Fahd Hospital of the University, University of Dammam, P.O. Box 439831952 Dammam, Eastern Province, Saudi Arabia Full list of author information is available at the end of the article
}

vertebral bodies $[5,6]$. The prognosis of $\mathrm{Em}$ is poor, with a 1-year survival rate of approximately $40 \%$ [7-9]. In this report, we present an unusual metastatic HCC case that initially presented as mastalgia caused by an EmHCC to the rib cage.

\section{Case presentation}

A 31-year-old housewife of African descent with a prior history of chronic hepatitis B infection and hypothyroidism presented with a mass in her left breast and mastalgia lasting for 6 months. Her vital signs were normal. Upon physical examination, a non-mobile, round mass of approximately $5 \times 6 \mathrm{~cm}$ was palpated in the left breast. The rest of the exam was normal, and assessment of other clinical parameters showed nothing unusual. However, laboratory findings showed an elevated serum $\alpha$-fetoprotein (AFP) level of $402.5 \mathrm{ng} / \mathrm{cc}$ and elevated alanine transaminase and aspartate transaminase levels of 94 and $651 \mathrm{IU} / \mathrm{L}$, respectively (Table 1).

Although diagnostic mammography findings were negative, a breast examination showed a retrograndular versus submuscular hypoechoic mass measuring 
Table 1 Biochemical test results and tumor marker levels

\begin{tabular}{lll}
\hline & Test & Result (normal range) \\
\hline CBC & Hemoglobin & $11.8(13.0-18.0) \mathrm{g} / \mathrm{dL}$ \\
& WBC count & $8.7(4.0-11.0) \mathrm{k} / \mu \mathrm{L}$ \\
LFT & Platelet & $150(140-450) \mathrm{k} / \mu \mathrm{L}$ \\
& Serum total protein & $6.1(6-8) \mathrm{g} / \mathrm{dL}$ \\
& Albumin & $2.3(3.5-5) \mathrm{g} / \mathrm{dL}$ \\
& SGOT & $651(15-37) \mathrm{U} / \mathrm{L}$ \\
SGPT & $94(14-63) \mathrm{U} / \mathrm{L}$ \\
LDH & $726(81-234) \mathrm{U} / \mathrm{L}$ \\
Gumor markers & GGTP & $376(5-55) \mathrm{U} / \mathrm{L}$ \\
& ALP & $238(46-116) \mathrm{U} / \mathrm{L}$ \\
& AFP & $402.5(0-40) \mathrm{ng} / \mathrm{mL}$ \\
& BHCG & $1.20(5-25) \mathrm{mlU} / \mathrm{mL}$ \\
& CA 125 & $27.7(<35) \mathrm{U} / \mathrm{mL}$ \\
CA 19-9 & $605.57(0-37) \mathrm{U} / \mathrm{mL}$ \\
CEA & $0.50(\leq 3) \mathrm{ng} / \mathrm{mL}$ \\
\hline
\end{tabular}

$5.2 \times 4.2 \times 5.4 \mathrm{~cm}$ in the left breast (Fig. 1). Consequently, the patient received a contrast chest and abdomen CT, which showed multifocal hypodense hepatic lesions with centralized necrosis and a tumoral thrombus in the intrahepatic portal vein (Fig. 2). A large, solitary mass with a large soft-tissue component was also seen on one of the patient's left ribs, which was accompanied by deterioration of the patient's 3rd rib bone. The mass bordered the ipsilateral pectoralis muscle, and it is likely that there was localized invasion (Fig. 3).
The patient subsequently received an image-guided needle biopsy of the mass. The biopsy specimen was subjected to specialized immunohistochemical staining (Fig. 4). The pathology report confirmed a metastatic epithelial tumor with morphological features that were hepatic in origin (Fig. 5).

\section{Discussion}

Accurate diagnosis is the 1st step in optimal cancer care. However, because EmHCC often presents atypically, patients might be misdiagnosed and not receive appropriate treatment in a timely manner. Moreover, distinguishing a primary cancer from secondary metastatic lesions can be challenging. Fortunately, the evolution of diagnostic imaging modalities can assist the physician in accurate diagnostic practices.

In our study, a contrast-enhanced CT scan of the chest showed a destructive lesion on the left 3rd rib as a large soft-tissue mass that anteriorly invaded the ipsilateral pectoralis muscle, causing localized invasion of the breast tissue. Moreover, a contrast-enhanced CT scan of the abdomen showed multifocal hypodense hepatic lesions with centralized necrosis that surrounded an enhanced pseudocapsule and distal branches of the portal vein, all of which are features suggestive of HCC [10].

Nevertheless, a noninvasive approach to diagnose EmHCC might not be sufficiently precise. Undoubtedly, immunohistochemical diagnosis from needle aspiration biopsy is the gold standard because it provides details about the neoplastic cells involved in the malignant disease process (e.g., arrangement pattern and stain confirmation). Our patient was diagnosed with stage IV HCC with a metastatic epithelial tumor to the 3rd rib.

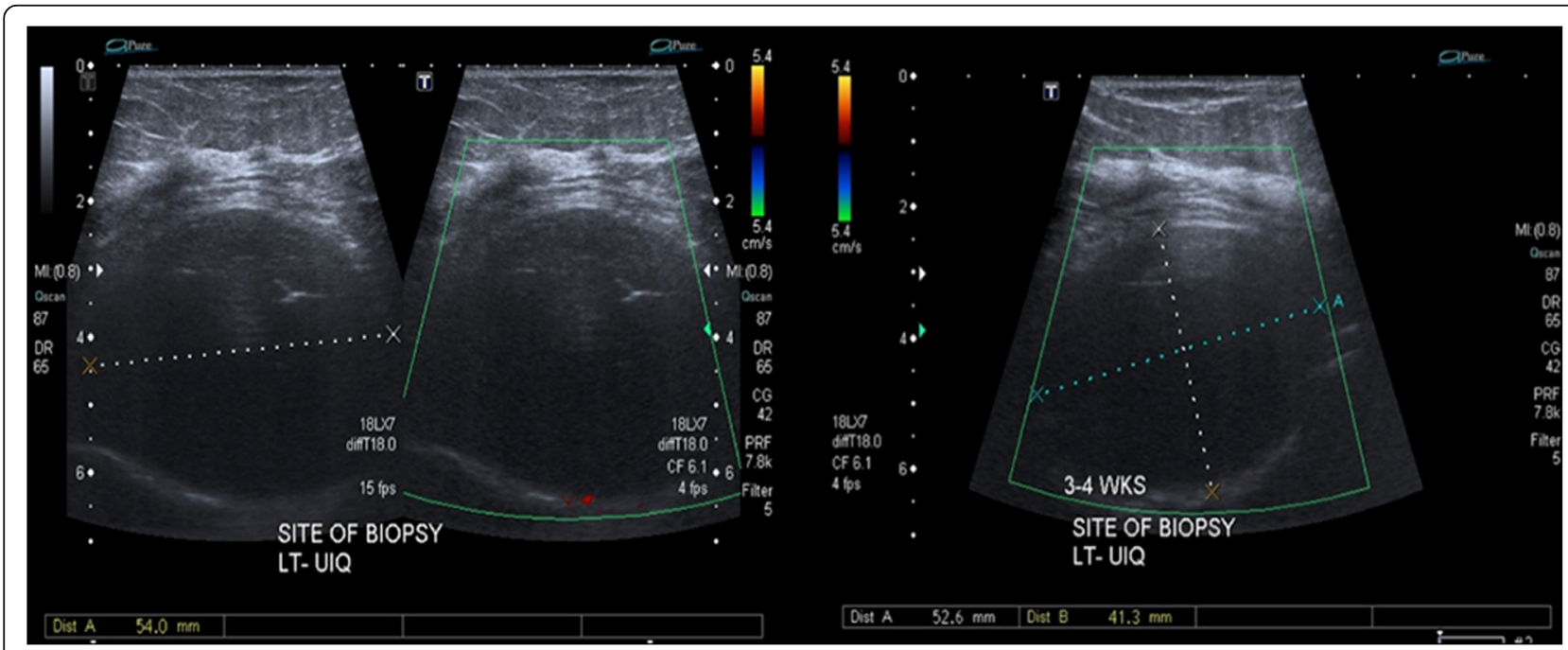

Fig. 1 Grayscale and Doppler ultrasound of the left breast exhibit a large $(5.2 \times 4.2 \times 5.4 \mathrm{~cm})$ hypoechoic/anechoic lesion located at the left retro-pectoralis region with no evidence of vascularity 


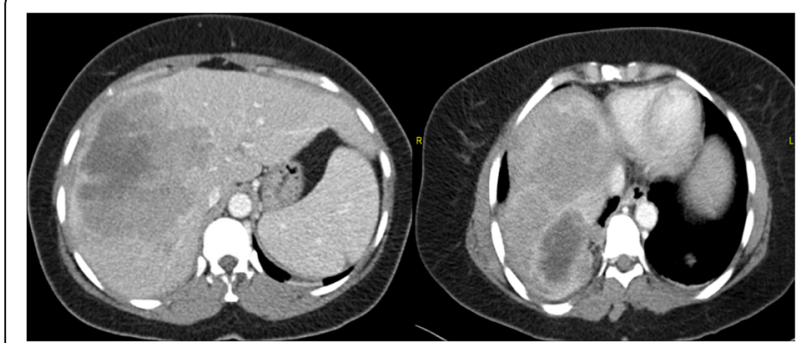

Fig. 2 Transaxial images of the contrast-enhanced CT scan of the abdomen at the portal venous phase shows a multifocal, ill-defined, and relatively hypodense hepatic lesion that involves the right and left hepatic lobes and surrounds an enhanced pseudocapsule. There are multiple subcapsular undulated margins, which are suggestive of subcapsular retraction. The lesions show mass effects on the intrahepatic portion of the IVC with significant narrowing and medial deviation. The indistinct appearance of the middle hepatic vein and the distal branches of the portal vein suggest that HCC invaded these areas
This diagnosis was confirmed by specialized immunohistochemical stains including Glypican-3, cytokeratin panantibody (Pan-CK), and cytokeratin 7 (CK7). Glypican-3 is a membrane-bound heparin sulfate proteoglycan that is expressed only in HCC cells and their metastases (Fig. 5) [11].

Interestingly, hepatocytes can grow in trabecular structures that are surrounded by tissue expressing high levels of ECM proteins such as laminin, vitronectin, collagen, and fibronectin [12]. The defective cell adhesion and migration and proteolysis of extracellular matrix proteins are necessary steps in metastatic development [13]. However, EmHCC can be disseminated either hematogenously or lymphatically to form new neoplastic foci in sites other than the original tumor [14].

The clinical course and prognosis of EmHCC are not entirely clear. However, recently developed management

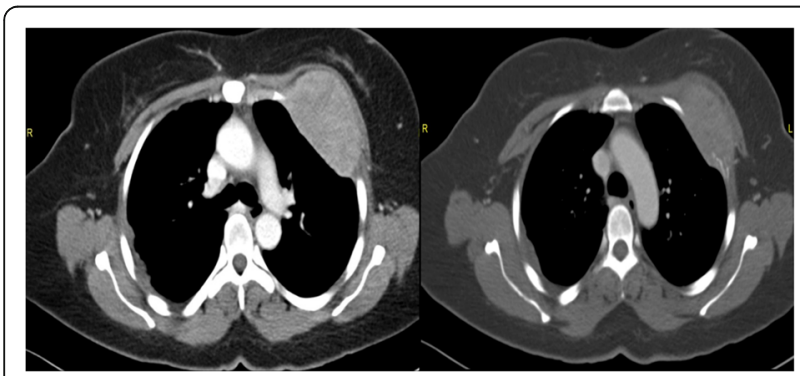

Fig. 3 Transaxial images of the contrast-enhanced CT scan of the chest. Left: mediastinal window. Right: bone window shows an aggressive, destructive bone lesion with a large soft-tissue component arising from the 3rd anterolateral rib, which invaded the adjacent pleural surfaces and the ipsilateral major pectoral muscle

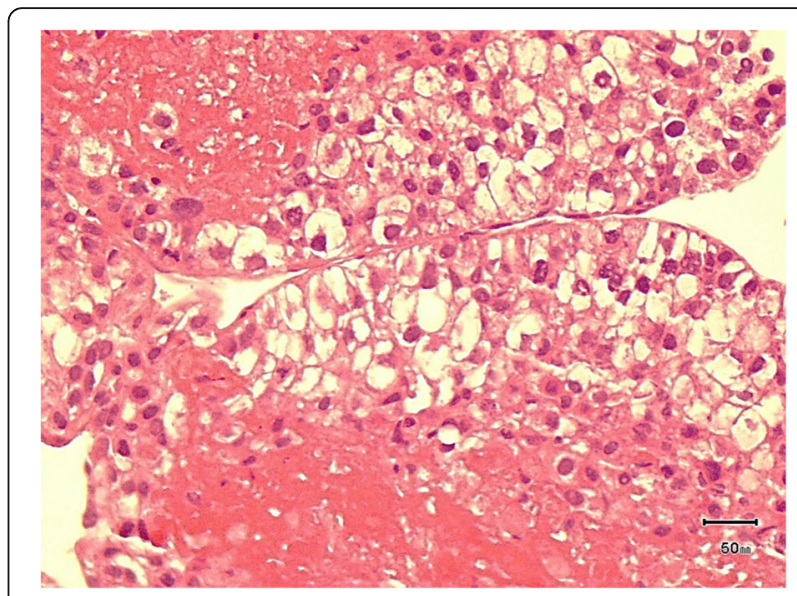

Fig. 4 Higher magnification show the details of the cancer cells, which are arranged in a trabecular sinusoidal pattern with a clear cytoplasm and pleomorphic nuclei. Mitoses are seen in some areas, as are some foci of necrosis

options can prolong the life expectancy of HCC patients. Furthermore, systemic therapy with sorafenib combined with 5-fluorouracil has shown promising effects for HCC treatment [15].

\section{Conclusions}

In summary, although EmHCC diagnosis can be challenging, physicians should be alert to the possibility of encountering this disease in their differential diagnoses. Regardless of AFP levels, EmHCC requires meticulous evaluation to reach an appropriate diagnosis and to provide suitable treatment.

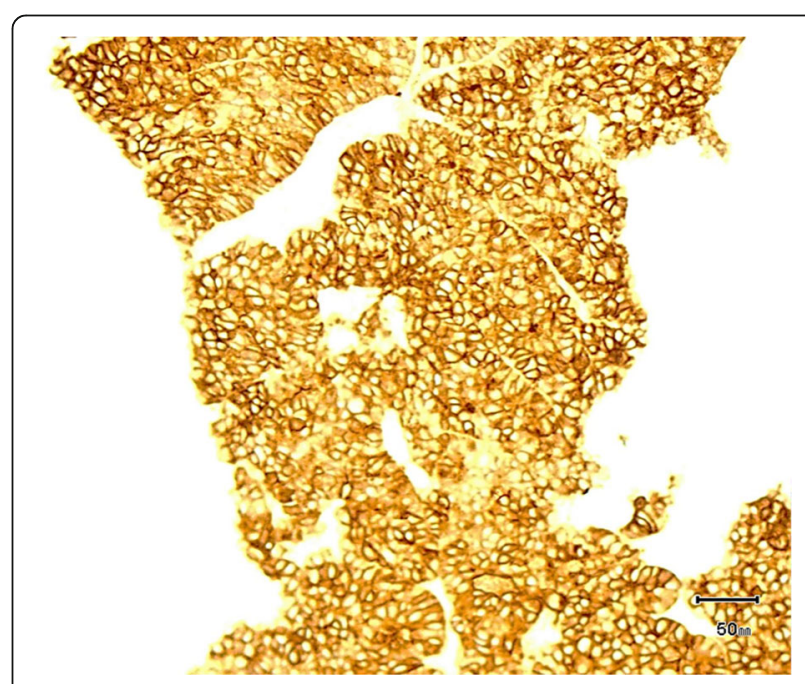

Fig. 5 Bone with hepatocellular metastases; the brown staining is positive for glypican 3, which is specific for HCC 


\section{Abbreviations}

AFP: Alpha fetoprotein; CK7: Cytokeratin 7; Em: Extrahepatic metastasis; EmHCC: Extrahepatic metastasis of hepatocellular carcinoma; HCC: Hepatocellular carcinoma; Pan-CK: Cytokeratin pan-antibody

\section{Acknowledgements}

The authors thank Dr. Abdullatif M. Almousa and Dr. Liga A. Almulla for providing the pathology images for this case presentation.

\section{Funding}

The authors declare that no funds have been received.

\section{Availability of data and materials}

The availability of the data and materials concerning the case report is related to the diagnostic examinations that were recorded during patient hospitalization. The publication of these data was authorized by the Affiliated King Fahd Hospital at the University of Dammam.

\section{Authors' contributions}

AMA-S wrote the original manuscript. MAES reported the pathology and interpreted the immunocytochemistry. Radiology image reporting was performed by AHA-A and IAA, and the revision of the final manuscript was performed by AMA-S and FAK. All authors read and approved the final manuscript.

\section{Competing interests}

The authors declare that they have no competing interests.

\section{Consent for publication}

Written informed consent was obtained from the patient for publication of their clinical details and radiological studies. A copy of the consent form is available for review by the editor of this journal.

\section{Ethics approval and consent to participate}

As per the University of Dammam Institutional Review Board, case reports do not need ethical approval or patient consent, as long as there is no intervention and no patient identifiers appear in the report. Therefore, neither ethical approval nor patient consent was required for this case report; however, written informed consent was obtained from the patient involved in this study.

\section{New software}

The authors declare that no new software has been used.

\section{Publisher's Note}

Springer Nature remains neutral with regard to jurisdictional claims in published maps and institutional affiliations.

\section{Author details}

'Department of Radiology, King Fahd Hospital of the University, University of Dammam, P.O. Box 439831952 Dammam, Eastern Province, Saudi Arabia. ${ }^{2}$ Department of Pathology, King Fahd Hospital of the University, University of Dammam, Dammam, Eastern Province, Saudi Arabia. ${ }^{3}$ Department of Emergency Medicine, King Fahd Hospital of the University, University of Dammam, Dammam, Eastern Province, Saudi Arabia.

Received: 7 October 2016 Accepted: 6 March 2017

Published online: 09 March 2017

\section{References}

1. Ministry of Health National Cancer Registry. Cancer Incidence Report-Saudi Arabia 1994-2010. 2014. ISSN: 1658-0559. http://www.chs.gov.sa/Ar/ mediacenter/NewsLetter/2010\%20Report\%20(1).pdf.

2. Goldman L, Ausiello DA, editors. Cecil medicine. Philadelphia: Saunders Elsevier; 2008

3. Bruix J, Sherman M. Management of hepatocellular carcinoma: an update. Hepatology. 2011:53(3):1020-2. doi:10.1002/hep.24199.

4. Si MS, Amersi F, Golish SR, Ortiz JA. Prevalence of metastases in hepatocellular carcinoma: risk factors and impact on survival. Am Surg. 2003;69(10):879.
5. Woo KM, Kim BC, Cho KT, Kim EJ. Spontaneous epidural hematoma from skull base metastasis of hepatocellular carcinoma. J Korean Neurosurg Soc. 2010;47(6):461-3.

6. El Thanaa AH, Radwan NA, Shaker M. Extrahepatic metastases as initial manifestations of hepatocellular carcinoma: an Egyptian experience. Diagn Pathol. 2015;10(1):82. doi:10.1186/s13000-015-0313-1.

7. Uka K, Aikata H, Takaki S, Shirakawa H, Jeong SC, Yamashina K, Hiramatsu A, Kodama H, Takahashi S, Chayama K. Clinical features and prognosis of patients with extrahepatic metastases from hepatocellular carcinoma. World J Gastroenterol. 2007;13(3):414. doi:10.3748/wjg.v13.i3.414.

8. Yang $Y$, Nagano $H$, Ota H, Morimoto O, Nakamura M, Wada H, Noda T, Damdinsuren B, Marubashi S, Miyamoto A, Takeda Y. Patterns and clinicopathologic features of extrahepatic recurrence of hepatocellular carcinoma after curative resection. Surgery. 2007;141(2):196-202. http://dx. doi.org/10.1016/..surg.2006.06.033.

9. Natsuizaka M, Omura T, Akaike T, Kuwata Y, Yamazaki K, Sato T, Karino Y, Toyota J, Suga T, Asaka M. Clinical features of hepatocellular carcinoma with extrahepatic metastases. J Gastroenterol Hepatol. 2005;20(11):1781-7. doi:10.1111/j.1440-1746.2005.03919.x.

10. Silverman PM, Szklaruk J. Controversies in imaging of hepatocellular carcinoma: multidetector CT (MDCT). Cancer Imaging. 2005;5(1):178-87. doi: 10.1102/1470-7330.2005.0105

11. Zaakook M, Ayoub M, Sinna EA, El-Sheikh S. Role of glypican-3 immunocytochemistry in differentiating hepatocellular carcinoma from metastatic carcinoma of the liver utilizing fine needle aspiration cytology. J Egypt Natl Canc Inst. 2013;25(4):173-80. http://dx.doi.org/10. 1016/j.jnci.2013.07.004.

12. Bianchi FB, Biagini G, Ballardini G, Cenacchi G, Faccani A, Pisi E, Laschi R, Liotta L, Garbisa S. Basement membrane production by hepatocytes in chronic liver disease. Hepatology. 1984;4(6):1167-72. doi:10.1002/hep. 1840040612.

13. Murphy G, Gavrilovic J. Proteolysis and cell migration: creating a path? Curr Opin Cell Biol. 1999;11(5):614-21. http://dx.doi.org/10.1016/S09550674(99)00022-8.

14. Katyal S, Oliver III JH, Peterson MS, Ferris JV, Carr BS, Baron RL. Extrahepatic metastases of hepatocellular carcinoma 1. Radiology. 2000;216(3):698-703. http://dx.doi.org/10.1148/radiology.216.3.r00se24698.

15. Deng L, Ren Z, Jia Q, Wu W, Shen H, Wang Y. Schedule-dependent antitumor effects of 5-fluorouracil combined with sorafenib in hepatocellular carcinoma. BMC Cancer. 2013;13(1):363. doi:10.1186/14712407-13-363.

\section{Submit your next manuscript to BioMed Central} and we will help you at every step:

- We accept pre-submission inquiries

- Our selector tool helps you to find the most relevant journal

- We provide round the clock customer support

- Convenient online submission

- Thorough peer review

- Inclusion in PubMed and all major indexing services

- Maximum visibility for your research

Submit your manuscript at www.biomedcentral.com/submit
Biomed Central 